\title{
The obesity epidemic: the role of addiction
}

\author{
Valerie H. Taylor MD PhD, Claire M. Curtis MA, Caroline Davis PhD
}

Previously published at www.cmaj.ca

$\mathrm{O}$ besity is a global health problem, and those affected require treatment by multidisciplinary treatment teams, including specialists from mental health, medicine and even surgery. Although the cause of obesity is multifaceted, it is clear that chronic overconsumption plays a fundamental role. When this type of overeating becomes compulsive and out of control, it is often classified as a "food addiction," a label that has caused much clinical and scientific controversy.'

The concept of addiction is complex, and the delineation of its defining characteristics has fostered considerable debate. Despite a lack of consensus, researchers nevertheless agree that the process involves a compulsive pattern of use, even in the face of negative health and social consequences. The concept of food addiction, which more accurately may reflect addiction to specific components of food, can be described in much the same way as other addictive behaviours. Both food and drugs induce tolerance over time, whereby increasing amounts are needed to reach and maintain intoxication or satiety. In addition, withdrawal symptoms, such as distress and dysphoria, often occur upon discontinuation of the drug or during dieting. There is also a high incidence of relapse with both types of behaviour. ${ }^{2}$ These symptoms in relation to food parallel to a remarkable extent those described in the Diagnostic and Statistical Manual of Mental Disorders (fourth edition) ${ }^{3}$ for substance abuse and dependence, which has led some to suggest that food addiction should be considered a psychiatric illness.'

Traditionally, the term "addiction" was applied solely to the abuse of drugs that activate the brain's mesolimbic reward pathways. In recent years, a broader conceptualization of addiction has emerged, and the term now includes so-called "behavioural addictions." This change has been based on research showing that the mesolimbic reward system is also activated by pleasurable behavioural activities. ${ }^{4}$ In fact, imaging studies have shown that specific areas of the mesolimbic system, such as the caudate nucleus, the hippocampus and the insula, are activated both by drugs and by food. Both also cause the release of striatal dopamine, a neurotransmitter that is an integral part of the reward system. Endogenous opiates, another group of players in the reward pathways, are also activated by drugs and by food - especially sweet foods whereas the opioid blocker naltrexone has been shown to reduce cravings for both. ${ }^{5}$ Compounds that act as inverse agonists within the endocannabinoid system have also been used both to treat substance addictions and to promote weight loss. ${ }^{6}$ Conversely, after treatment for obesity by means of gastric surgery, subsets of patients may experience other addictive

\section{Key points}

- The causes of obesity are complex and specific to the individual.

- The core diagnostic constructs and neurologic findings linked to substance abuse are shared by some individuals with weight problems.

- Therapies traditionally applied to the area of addiction may be helpful in managing weight problems.

behaviours such as gambling or compulsive spending.? This phenomenon, known as "transfer of addictions," requires further study but does suggest that, for some individuals, the tendency toward addiction may be hard-wired.

In an attempt to explain the motivation for some cases of compulsive overeating, researchers have proposed that highly palatable foods, such as those that are sweet, salty or high in fat, have the potential for abuse in a manner similar to conventional drugs. ${ }^{8}$ From an evolutionary perspective, it would have been highly adaptive for the consumption of food to be rewarding, especially in the case of foods rich in fat and sugar, since they can be rapidly converted into energy. ${ }^{9}$ A widely accepted theory postulates that the mesolimbic reward pathway evolved to reinforce the motivation to approach and engage in naturally rewarding behaviours such as eating, thereby promoting survival in times of famine. ${ }^{2}$ Over the last few generations, however, our food environment has changed radically. Recent developments in food technologies have allowed the creation and modification of certain foods to artificially enhance their rewarding properties (i.e., their palatability) in an attempt to increase sales in a highly competitive market. ${ }^{10}$ In addition, calorie-dense, high-fat foods have become abundant and readily accessible in most Western societies. ${ }^{11}$ Food also differs from many other addictive substances because it is legal and relatively cheap. This accessibility, in combination with our innate preferences for such foods, can be used to exploit vulnerable individuals and to increase the likelihood that people will "misuse" food, in much the same way that addicts misuse other addictive substances.

Not everyone who is exposed to drugs becomes an addict, and, similarly, not everyone who is exposed to high-fat, highcalorie foods becomes a compulsive overeater. These differences in susceptibility can be attributed, in part, to a genetic

From the Department of Psychiatry and Behavioural Neuroscience (Taylor), McMaster University, Hamilton, Ont.; and the Department of Kinesiology and Health Sciences (Curtis, Davis), York University, Toronto, Ont.

CMAJ 2009. DOI:10.1503/cmaj.091142

All editorial matter in CMAJ represents the opinions of the authors and not necessarily those of the Canadian Medical Association. 
predisposition and/or to brain adaptations to excessive use over time, specifically, downregulation of the dopamine $\mathrm{D}_{2}$ receptors linked to addictive behaviour. ${ }^{12}$ Vulnerability may also stem from various personality traits. For example, obese individuals tend to be more sensitive to reward and punishment and to display more impulsive behaviours. ${ }^{13}$ For these individuals, the forces driving food consumption are likely to go beyond physiologic hunger. Highly palatable foods may produce pleasure and reduce pain in a manner similar to other addictive substances. Research also suggests that eating is commonly used as a method of self-medication in response to negative emotional states, such as depression, anxiety, loneliness, boredom, anger and interpersonal conflict. ${ }^{14}$

The concept of addiction does not negate the role of free will and personal choice. It may, however, provide insight into why a subset of individuals with obesity continue to struggle. ${ }^{2}$ Classifying obesity as an addiction is a strong statement and implies much more than merely a change in semantics. It indicates that screening for addiction and binge eating should become a routine part of treatment for obesity, and, in the case of gastric surgery, that such screening should be an important part of postoperative follow-up. It also may explain the lack of success of lifestyle programs that do not incorporate pharmacotherapy or behavioural strategies specifically designed to address the addictive component of this illness. Interestingly, there is considerable overlap among the medications shown to interfere with food and drug abuse in animal models, and similar behavioural interventions motivational interviewing, cognitive behavioural therapy and 12step programs - are used in the treatment of both conditions.

The current "blame" mentality that is often applied to individuals with obesity needs to be re-examined. Although medicine may not yet accept compulsive overeating as an addiction, we cannot ignore evidence highlighting the role played by biologic vulnerability and environmental triggers. To do so would represent a clinical disservice.

This article was peer reviewed.
Competing interests: Caroline Davis received funding for travel and accommodation from the Canadian Obesity Network to present aspects of this paper at the first Obesity Summit. None declared for Valerie Taylor and Claire Curtis.

Contributors: All authors contributed to the concept for this article and to the development and editing of the text, and all approved the final version submitted for publication.

Funding: For work related to this commentary, Caroline Davis was partially supported by a grant from the Canadian Institutes of Health Research.

\section{REFERENCES}

1. Davis C, Carter JC. Compulsive overeating as an addiction disorder. A review of theory and evidence. Appetite 2009;53:1-8.

2. Volkow ND, O'Brien CP. Issues for DSM-V: Should obesity be included as a brain disorder? Am J Psychiatry 2007;164:708-10.

3. Diagnostic and statistical manual of mental disorders. 4th ed. Arlington (VA): American Psychiatric Association; 1994.

4. Kelley AE, Schiltz CA, Landry CF. Neural systems recruited by drug- and foodrelated cues: studies of gene activation in corticolimbic regions. Physiol Behav 2005;86:11-4.

5. Yeomans MR, Gray RW. Effects of naltrexone on food intake and changes in subjective appetite after eating: evidence for opioid involvement in the appetizer effect. Physiol Behav 1997;62:15-21.

6. Pelchat ML. Food addiction in humans. J Nutr 2009;139:620-2.

7. Sogg S. Alcohol misuse after bariatric surgery: epiphenomenon or "Oprah" phenomenon? Surg Obes Relat Dis 2007;3:366-8.

8. Salamone JD, Correa M, Mingote S, et al. Nucleus accumbens dopamine and the regulation of effort in food-seeking behavior: implications for studies of natural motivation, psychiatry, and drug abuse. J Pharmacol Exp Ther 2003;305:1-8.

9. Erlanson-Albertsson C. [Sugar triggers our reward-system. Sweets release opiates which stimulates the appetite for sucrose - insulin can depress it.] Lakartidningen 2005;102:1620-2, 1625, 1627. Swedish.

10. Kessler D. The end of overeating: taking control of the insatiable North American appetite. Toronto (ON): McClelland and Stewart; 2009.

11. Monsivais P, Drewnowski A. The rising cost of low-energy-density foods. $J \mathrm{Am}$ Diet Assoc 2007;107:2071-6.

12. Roberts AJ, Koob GF. The neurobiology of addiction: an overview. Alcohol Health Res World 1997;21:101-6.

13. Davis C, Levitan RD, Carter J, et al. Personality and eating behaviors: a casecontrol study of binge eating disorder. Int J Eat Disord 2008;41:243-50.

14. Davis C, Strachan S, Berkson M. Sensitivity to reward: implications for overeating and overweight. Appetite 2004;42:131-8.

Correspondence to: Dr. Valerie H. Taylor, Department of

Psychiatry and Behavioural Neuroscience, McMaster University,

Hamilton ON L8N 3K7; taylorv@mcmaster.ca

\section{Atacand}
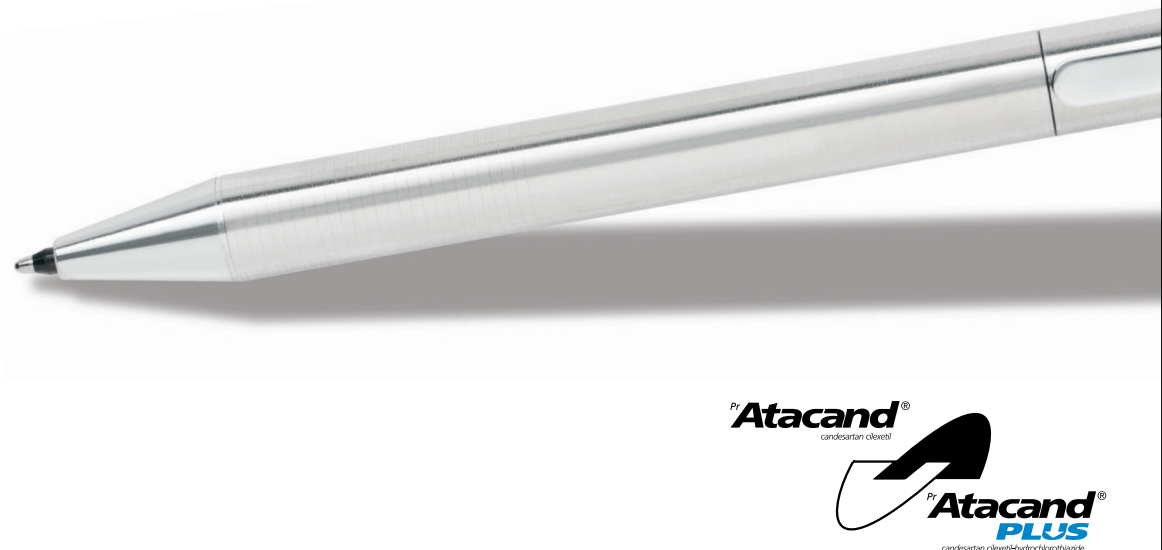